\title{
Population dynamics of aberrant chromosome 1 in mice
}

\author{
IGOR SABANTSEV, OLEG SPITSIN, SERGEI AGULNIK \& ANATOLY RUVINSKY* \\ Institute of Cytology and Genetics, Siberian Department of Russian Academy of Sciences, Novosibirsk 630090, Russia
}

\begin{abstract}
Natural populations of two semispecies of house mouse, Mus musculus domesticus and M.m. musculus, were found to be polymorphic for an aberrant chromosome 1 bearing a large inserted block of homogeneously staining heterochromatin. Strong meiotic drive for the aberrant chromosome from M.m. musculus was previously observed in heterozygous female mice. There are at least three meiotic drive levels determined by different allelic variants of distorter. Homozygotes had low viability and females showed low fertility. Both homo- and heterozygous males had normal fertility and their segregation patterns did not deviate from normal. Computer simulations were performed of the dynamics of aberrant chromosome 1 in demes and populations. The data demonstrate that a spontaneous mutation (inversion) of an aberrant chromosome 1, once arisen, has a high probability of spreading in a population at high coefficients of meiotic drive and migration. In the long-term, the population attains a stationary state which is determined by the drive level and migration intensity. The state of stable genotypic equilibrium is independent of deme and population size, as well as of the initial concentration of the aberrant chromosome. As populations initially polymorphic for the distorters approach the stationary state, the stronger distorter is eliminated. The frequencies of the aberrant chromosome determined by computer analysis agree well with those obtained for the studied Asian M.m. musculus populations. The evolutionary pathways for the origin and fixation of the aberrant chromosome in natural populations are considered.
\end{abstract}

Keywords: Chromosome 1 in mice, computer simulation, meiotic drive, Mus musculis, population dynamics.

\section{Introduction}

Bearers of chromosome 1 with insertions have been found in natural populations of the European semispecies of Mus musculus domesticus (Traut et al., 1984) and the Asian M.m. musculus (Agulnik et al., 1988; Yakimenko \& Korobitsyna, 1988; Winking et al., 1991a). The extra segment attains 30 per cent of the length of normal chromosome 1 . The region containing it stains homogeneously with the C-method. A single insertion has been observed in M.m. domesticus while an inversion separating the segment into two closely adjacent blocks has been described in M.m. musculus (Agulnik et al., 1990b; Winking et al., 1991b). Potent meiotic drive favouring chromosome 1 has been reported in M.m. musculus heterozygotes for the inserts on this chromosome (Agulnik et al., 1990a). The transmission level of the insertion-carrying chromosome 1 varies from 50 to 85 per cent, dependent on the genotype of the female. The transmission

Correspondence: A. Ruvinsky, Koninginnerweg 140, 1075 EC, Amsterdam, The Netherlands. level appears to be related to the presence of a particular distorter variant located in chromosome 1 and acting in the trans-position (Agulnik et al., 1993, a). The viability of homozygotes is reduced to 55 per cent, and the fertility of homozygous females is as low as about 10 per cent. The fertility of hetero- and homozygous males is quite high. Thus, the system has a set of features similar to others previous described for meiotic drive (Crow, 1988; Silver, 1985; Brittnacher \& Ganetzky, 1989).

Based on the available genetic data, we carried out a computer analysis of the population dynamics of chromosome 1 with the insertions. The results obtained allowed us to compare the genotype frequencies derived from the model with those actually observed in nature. The validity of an approach of this kind has been demonstrated by Lewontin \& Dunn (Lewontin \& Dunn, 1960; Lewontin, 1962) who have studied the genotype dynamics of mouse T-haplotypes undergoing meiotic drive. The aim of this study was to determine the range of estimates for parameters contributing to the spreading and maintenance of aberrant chromosome 1 in demes and populations. 


\section{Materials and methods}

The Monte Carlo procedure was used to analyse a stochastic model of the population dynamics of chromosome 1 with the insertions. Evenly distributed random numbers were generated by the computer. These numbers lay between zero and one, with any value of $V_{\mathrm{i}}$ being equally probable within this interval (Dyakonov, 1987). The Monte Carlo method was applied to analyse simulation of random chromosome segregation, selection of parents of the next generation, selection of parental pairs, death of homozygotes, male migration, polymorphism of distorters and other processes.

The following experimental data were used to construct the computer model: three levels of the preferential transmission of the aberrant chromosome 1 by heterozygous females; high ( 85 per cent), intermediate (64 per cent), and low ( 50 per cent); death of homozygotes ( 45 per cent); fertility of homozygous females (10 per cent). We considered models of (a) an isolated deme, and (b) a population consisting of 100 demes, with males migrating from deme to deme (Fig. 1).
Variants of 'large' (10 $\sigma^{\circ} \times 10 \%$ 우 $)$ and 'small' $\left(3 \sigma^{\circ} \times 6\right.$ 우) demes were examined in the first situation of an isolated deme. At the start, a deme appears with a single heterozygous male, the genotype of all the other individuals is assumed to be normal. The choice of the parental pairs follows. The number of females with which a male can randomly mate varies from 0 to $n$, where $n=6$ or 10 . The pool of zygotes is then formed. Genetic segregation rules and fertility of homozygotes are also taken into account. The number of offspring a female can produce is six. This is followed by choice of mice involved in the production of the subsequent generation $\left(3 \sigma^{A}+6 \%\right.$ or $1000+10$ o $)$ from the pool, thereafter the cycle is repeated. The number of generations thus passed is 300 , the number of runs is 100 for a population and 1,000 for a deme (Fig. 1a). Simulation is performed under the assumption that the generations do not overlap.

The parameters used to construct the second model were as follows. The population consisted of 100 $\left(30^{*} \times 6 \%\right.$ ) demes randomly distributed over the display. At the start, in a randomly taken deme, there is

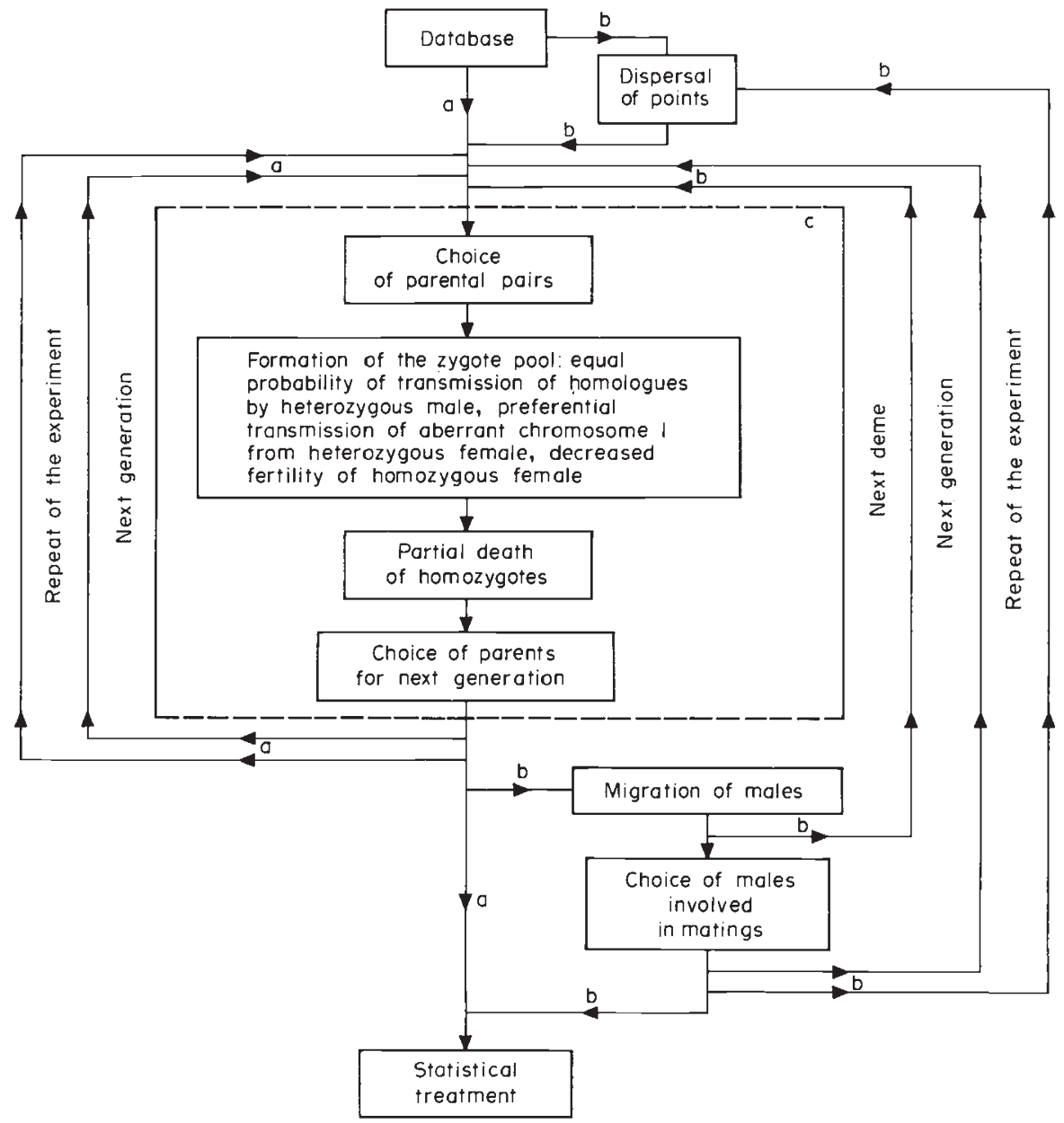

Fig. 1 A scheme for the simulation of the population dynamics of aberrant chromosome 1 in (a) a single isolated deme, 300 generations, 1,000 repeated experiments; (b) a population consisting of 100 demes, 300 generations, 100 repeats; (c) a single deme, one generation. 
a single heterozygote for the aberrant chromosome 1, a male, other mice have the normal genotype. Parental pairs are chosen for each deme. The offspring pool is formed by the procedure described in Fig. 1(c). The next step is to choose six males and six females from the offspring pool; one or three males migrate to the nearest deme (the respective migration coefficients are $k=0.08$ and $k=0.25$ ). These migrants can be chosen as parents of the next generation. The selection of local males in preference to migrant males is set $(1: 0.8)$. Three males are randomly taken for reproduction at the last step. Each deme is subjected to the procedure, the cycle is repeated for the next generation. The number of generations thus passed is 300 , and the number of runs is 100 (Fig. 1b). We finally analysed population dynamics at different levels of the meiotic drive. We simulated three variants of populations monomorphic for the distorter responsible for the level of meiotic drive $(0.85,0.64$ and 0.5$)$ and also three polymorphic variants $(0.85 / 0.64,0.85 / 0.5,0.64 / 0.5)$.

The computer used was an IBM PC AT. The simulation programs and statistical treatment of the results were carried out in TURBO-PASCAL and GW-BASIC languages.

Wild mice were captured in localities distributed over the eastern part of the country. Standard methods were used for karyotype analysis (Dyban \& Baranov, 1978).

\section{Results}

Population dynamics of aberrant chromosome 1 in a single deme

Natural populations of mice exist as small family groups known as demes (Lewontin \& Dunn, 1960). The size of the demes, the time of their existence and the intensity of contacts of a deme with others vary greatly depending upon their conditions. Nevertheless, they are often treated as stable components of natural mouse populations. Thus, it is reasonable to first simulate the dynamics of genetic processes in a single deme and then those that occur at the population level.

We analysed the frequency dynamics of aberrant chromosome 1 in demes composed of $30^{\circ} 0^{\prime}$ and 6 우우, the highest offspring number in each generation is 36 ('small' demes) and $10 \sigma^{\circ} \sigma^{\circ}$ and $10 \%$, the highest number is 60 ('large' demes). These deme sizes conform with the ones observed in nature (Petras, 1967). Figure 2 presents the elimination rate of the aberrant chromosome from the 'large' and 'small' demes at different meiotic drive levels for 300 generations. There is a consistent sharp decrease in the number of demes retaining at least one aberrant chromosome 1 for the first $10-15$ generations. It is obvious that elimination is much stronger in the 'large' (Fig. 2b,d) rather than in the 'small' (Fig. 2a,c) demes; the reason being the different initial concentration of the aberrant chromosome in the demes $11: 40$ in the 'large' and 1:18 in the 'small' demes). The results were expected and may appear trivial. They are important, however, to further our line of reasoning and to give a straightforward answer to the question 'does a spontaneous mutation, once arisen, have a good chance of spreading in a small deme?'. The meiotic drive level becomes more important than deme size in subsequent generations; thus, after $10-15$ generations, at a drive coefficient $m=0.85$, elimination ceases almost completely. In demes with a low meiotic drive $(m=0.64)$, the aberrant chromosome is eliminated at a high rate so that it is completely lost by generation 100 . Two phases can be distinguished in the process: during the first (10-15 generations) the frequency of the aberrant chromosome continues to increase (Fig. 3), and its elimination level is a maximum (Fig. 2), and during the second the frequency of the aberrant chromosome becomes stable and elimination smoothly declines in demes with the persistent aberrant chromosome. The dynamics of the average frequencies of the aberrant chromosome for the 'large' demes are similar to those described for the 'small' demes.

Computer data demonstrate that after generation $10-15$ an equilibrium of genotype frequencies can be established in demes with $m=0.85$ and that it is stably maintained thereafter (Fig. 3a). The genetic parameters of the demes were calculated for generations 20-70 because in the subsequent demes, with a meiotic drive level of 0.64 , the aberrant chromosome was almost entirely lost and therefore comparative analysis of the

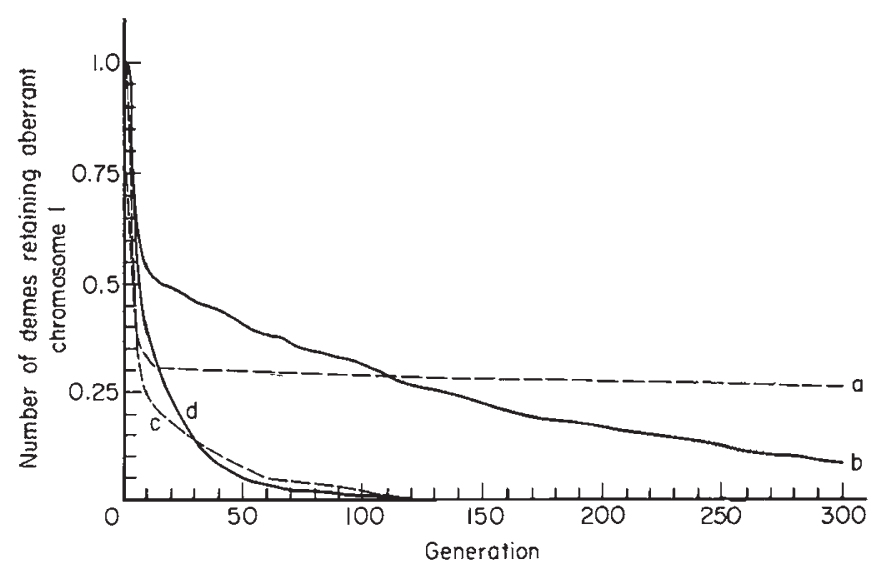

Fig. 2 The elimination rate of aberrant chromosome 1 in (a) $m=0.85$, 'large' deme; (b) $m=0.85$, 'small' deme; (c) $m=0.64$, 'large' deme; (d) $m=0.64$, 'small' deme. 
average frequencies was performed in that interval (Table 1). The calculations given in Table 1 show that the 'large' and 'small' demes with the same level of meiotic drive differ only slightly, if at all, in average genotype frequencies. However, aberrant chromosome concentration and hetero-, homozyote frequencies in the demes are significantly higher at a meiotic drive coefficient of 0.85 than 0.64 .

It should be stipulated that the frequencies of the aberrant chromosomes in some simulations were quite close both in demes with $m=0.85$ and those with $m=0.64$ (Table 2), the average values for each simulation differed little from the total average value (Table 1). Each of five randomly taken demes with $m=0.85$, which had retained the aberrant chromosome for at least 70 generations, attained a stable stationary state from about generation 10 . The deviation from average of the aberrant chromosome was slight for such demes.

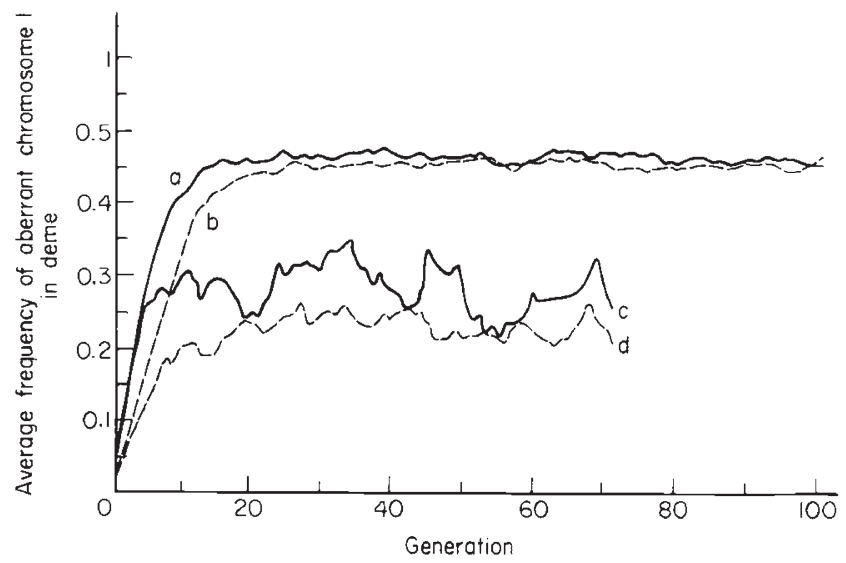

Fig. 3 The dynamics of the average frequency of aberrant chromosome 1 in demes retaining it by generation 100 $(m=0.85)$ of $70(m=0.64)$. (a) $m=0.85$, 'small' deme, 309 demes from 1,000; (b) $m=0.85$, 'large' deme, 287 demes; (c) $m=0.64$, 'small' deme, 21 demes; (d) $m=0.64$, 'large' deme, 41 demes.
The stationary state was not established in demes with $m=0.64$.

\section{Aberrant chromosome dynamics in the simulated population}

In this analysis of the dynamics of genotype frequencies in isolated demes, it appeared expedient to proceed with examination of the parameters in large simulated populations consisting of a greater number of demes interconnected through migration. We then present the results of simulation in populations consisting of 100 'small' demes with the use of the above procedure.

We then analysed the spreading probability of the aberrant chromosome in a population in which there is initially a single heterozygous bearer of the aberrant chromosome. As the data of Table 3 show, at a low migration coefficient $(k=0.08)$, the aberrant chromosome spreads less rapidly in the population and the number of populations where the chromosomes did not eliminate is smaller. Thus, we will examine in detail the dynamics of genetic processes with a high migration coefficient $(k=0.25)$. Figure 4 shows how the dynamics of the elimination of the aberrant chromosome changes with each of the six possible combinations of distorter determining the strength of meiotic drive. At first, for 10-15 generations, the aberrant chromosome is eliminated from the population as in the demes. This fulfils expectation because during this time interval the aberrant chromosome is fixed in the population (Fig. 2 ). The populations with distorters $0.85 / 0.85,0.85 /$ 0.64 and $0.64 / 0.64$, in which the chromosome persists for the first 15-20 generations, further remain stably polymorphic (Fig. $4 \mathrm{a}-\mathrm{c}$ ). The populations with distorter 0.5 all lose the aberrant chromosome by generation 50. The two remaining population variants $(0.85 / 0.5$ and $0.64 / 0.5)$ continue to lose the aberrant chromosome for 30 generations. Thus we will deal with only the first three types of population. About 99

Table 1 The average concentrations of aberrant chromosome 1 and genotype frequencies in a single deme from generation $20-70$

\begin{tabular}{|c|c|c|c|c|c|}
\hline $\begin{array}{l}\text { Meiotic } \\
\text { drive } \\
\text { coefficient, } \\
\text { deme size }\end{array}$ & $\begin{array}{l}\text { Number of demes } \\
\text { retaining the } \\
\text { aberrant chromosome } \\
\text { by generation } 70^{*}\end{array}$ & \multicolumn{3}{|c|}{ Genotype frequencies $(\%)$} & $\begin{array}{l}\text { Aberrant } \\
\text { chromosome } 1 \\
\text { concentration } \\
(\%)\end{array}$ \\
\hline 0.85 large & 295 & $0.11 \pm 0.00$ & $0.68 \pm 0.01$ & $0.21 \pm 0.01$ & $0.45 \pm 0.01$ \\
\hline 0.85 small & 375 & $0.11 \pm 0.01$ & $0.68 \pm 0.01$ & $0.21 \pm 0.01$ & $0.46 \pm 0.01$ \\
\hline
\end{tabular}

*From 1,000 initial demes. 
Table 2 Frequencies of aberrant chromosome 1 on randomly taken demes retaining it by generation 70

\begin{tabular}{|c|c|c|c|c|c|c|c|c|c|c|}
\hline \multirow[b]{2}{*}{ Generation } & \multicolumn{5}{|c|}{0.64 small } & \multicolumn{5}{|c|}{0.64 large } \\
\hline & I & II & III & IV & V & I & II & III & IV & V \\
\hline 0 & 0.06 & 0.06 & 0.06 & 0.06 & 0.06 & 0.03 & 0.03 & 0.03 & 0.03 & 0.03 \\
\hline 10 & 0.23 & 0.29 & 0.45 & 0.26 & 0.19 & 0.42 & 0.13 & 0.15 & 0.04 & 0.26 \\
\hline 20 & 0.17 & 0.26 & 0.21 & 0.18 & 0.38 & 0.22 & 0.23 & 0.33 & 0.22 & 0.05 \\
\hline 30 & 0.10 & 0.26 & 0.24 & 0.40 & 0.40 & 0.22 & 0.28 & 0.37 & 0.14 & 0.34 \\
\hline 40 & 0.14 & 0.29 & 0.38 & 0.35 & 0.40 & 0.19 & 0.10 & 0.35 & 0.15 & 0.20 \\
\hline 50 & 0.15 & 0.07 & 0.15 & 0.28 & 0.34 & 0.18 & 0.08 & 0.23 & 0.49 & 0.18 \\
\hline 60 & 0.26 & 0.33 & 0.13 & 0.25 & 0.08 & 0.08 & 0.23 & 0.25 & 0.21 & 0.08 \\
\hline 70 & 0.42 & 0.48 & 0.46 & 0.19 & 0.06 & 0.30 & 0.36 & 0.04 & 0.07 & 0.22 \\
\hline \multirow[t]{4}{*}{ Average } & 0.24 & 0.33 & 0.27 & 0.28 & 0.33 & 0.17 & 0.23 & 0.22 & 0.25 & 0.23 \\
\hline & \pm 0.13 & \pm 0.16 & \pm 0.14 & \pm 0.10 & \pm 0.14 & \pm 0.08 & \pm 0.12 & \pm 0.10 & \pm 0.11 & \pm 0.10 \\
\hline & \multicolumn{5}{|c|}{0.85 small } & \multicolumn{5}{|c|}{0.85 large } \\
\hline & I & II & III & IV & V & I & II & III & IV & V \\
\hline 0 & 0.06 & 0.06 & 0.06 & 0.06 & 0.06 & 0.03 & 0.03 & 0.03 & 0.03 & 0.03 \\
\hline 10 & 0.56 & 0.43 & 0.52 & 0.43 & 0.41 & 0.41 & 0.17 & 0.40 & 0.58 & 0.51 \\
\hline 20 & 0.43 & 0.55 & 0.35 & 0.74 & 0.44 & 0.46 & 0.33 & 0.42 & 0.41 & 0.51 \\
\hline 30 & 0.44 & 0.56 & 0.52 & 0.37 & 0.42 & 0.43 & 0.56 & 0.37 & 0.47 & 0.44 \\
\hline 40 & 0.39 & 0.55 & 0.61 & 0.39 & 0.54 & 0.55 & 0.59 & 0.58 & 0.26 & 0.48 \\
\hline 50 & 0.50 & 0.56 & 0.07 & 0.34 & 0.52 & 0.60 & 0.26 & 0.39 & 0.58 & 0.35 \\
\hline 60 & 0.14 & 0.40 & 0.33 & 0.32 & 0.52 & 0.36 & 0.49 & 0.26 & 0.45 & 0.50 \\
\hline 70 & 0.22 & 0.28 & 0.54 & 0.52 & 0.48 & 0.33 & 0.49 & 0.23 & 0.51 & 0.50 \\
\hline \multirow[t]{2}{*}{ Average } & 0.36 & 0.51 & 0.43 & 0.39 & 0.50 & 0.47 & 0.50 & 0.41 & 0.45 & 0.44 \\
\hline & \pm 0.13 & \pm 0.10 & \pm 0.16 & \pm 0.09 & \pm 0.08 & \pm 0.08 & \pm 0.07 & \pm 0.11 & \pm 0.09 & \pm 0.09 \\
\hline
\end{tabular}

Table 3 The average concentrations of aberrant chromosome 1 and genotype frequencies in populations from generations $250-300$

\begin{tabular}{|c|c|c|c|c|c|c|}
\hline \multirow[b]{2}{*}{$\begin{array}{l}\text { Distorters } \\
\text { in } \\
\text { population }\end{array}$} & \multirow[b]{2}{*}{$\begin{array}{l}\text { Migration } \\
\text { coefficient }\end{array}$} & \multirow{2}{*}{$\begin{array}{l}\text { Number of } \\
\text { populations } \\
\text { retaining the } \\
\text { aberrant } \\
\text { chromosome by } \\
\text { generation } 300\end{array}$} & \multicolumn{3}{|c|}{ Spreading rate of the aberrant chromosome in population } & \multirow[b]{2}{*}{$\begin{array}{l}\text { Concentration } \\
\text { of aberrant } \\
\text { chromosome } 1 \\
(\%)\end{array}$} \\
\hline & & & $\begin{array}{l}\text { Generation } \\
\text { number } \\
\text { attainment } \\
\text { of maximum* }\end{array}$ & $\begin{array}{l}\text { Number of demes } \\
\text { with the aberrant } \\
\text { chromosome at the } \\
\text { maximum point }\end{array}$ & $\begin{array}{l}\text { Number of demes } \\
\text { with the aberrant } \\
\text { chromosome by } \\
\text { generation } 300\end{array}$ & \\
\hline $0.85-0.85$ & $\begin{array}{l}0.25 \\
0.08\end{array}$ & $\begin{array}{l}47 \\
49\end{array}$ & $\begin{array}{l}140 \\
250\end{array}$ & $\begin{array}{l}99 \\
98\end{array}$ & $\begin{array}{l}99 \\
98\end{array}$ & $\begin{array}{l}0.44 \pm 0.00 \\
0.43 \pm 0.00\end{array}$ \\
\hline $0.85-0.64$ & $\begin{array}{l}0.25 \\
0.08\end{array}$ & $\begin{array}{l}34 \\
30\end{array}$ & $\begin{array}{l}220 \\
230\end{array}$ & $\begin{array}{l}76 \\
47\end{array}$ & $\begin{array}{l}72 \\
40\end{array}$ & $\begin{array}{l}0.14 \pm 0.00 \\
0.09 \pm 0.00\end{array}$ \\
\hline $0.64-0.64$ & $\begin{array}{l}0.25 \\
0.08\end{array}$ & $\begin{array}{r}22 \\
2\end{array}$ & $\begin{array}{l}290 \\
240\end{array}$ & $\begin{array}{l}66 \\
22\end{array}$ & $\begin{array}{l}66 \\
15\end{array}$ & $\begin{array}{l}0.12 \pm 0.00 \\
0.03 \pm 0.00\end{array}$ \\
\hline $0.85-0.5$ & $\begin{array}{l}0.25 \\
0.08\end{array}$ & $\begin{array}{r}10 \\
2\end{array}$ & $\begin{array}{r}90 \\
260\end{array}$ & $\begin{array}{l}30 \\
28\end{array}$ & $\begin{array}{r}6 \\
16\end{array}$ & $\begin{array}{l}0.03 \pm 0.01 \\
0.04 \pm 0.01\end{array}$ \\
\hline $0.64-0.5$ & $\begin{array}{l}0.25 \\
0.08\end{array}$ & $\begin{array}{l}1 \\
0\end{array}$ & 230 & 19 & $\frac{14}{-}$ & $\begin{array}{l}0.04 \pm 0.01 \\
-\end{array}$ \\
\hline
\end{tabular}

*The generation at which the maximum of demes with the aberrant chromosome in the population is attained. 


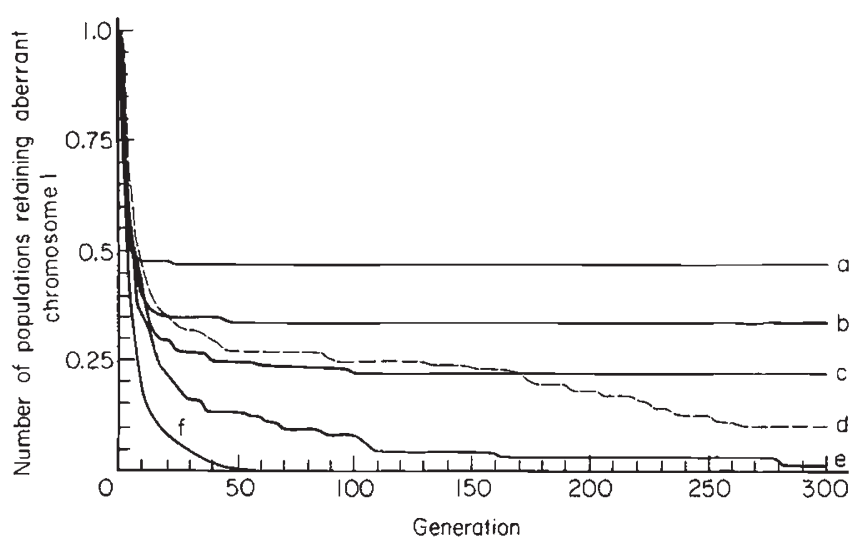

Fig. 4 The elimination rate of aberrant chromosome 1 in population with migration coefficient $k=0.25$ and distorters. (a) $0.85 / 0.85$; (b) $0.85 / 0.64$; (c) $0.64 / 0.64$; (d) $0.85 / 0.5$; (e) $0.64 / 0.5 ;$ (f) $0.5 / 0.5$.

per cent of the demes in the population monomorphic for distorter 0.85 have the aberrant chromosome by generation 140 (Table 3 ). In populations $0.85 / 0.64$ and $0.64 / 0.64$, the aberrant chromosome spreads less rapidly from deme to deme (by generations 220 and 290 , respectively) and to a smaller number ( 76 and 85 demes, respectively) (Table 3 ).

The dynamics of the average frequencies of the aberrant chromosome are shown in Fig. 5. The increase in the average frequencies drastically increases in population $0.85 / 0.85$, which reaches a stationary state by generation 140 . The equilibrium frequency of the aberrant chromosome is 0.44 in this population (Table 4). Populations $0.85 / 0.64$ and $0.64 /$ 0.64 reach about the same frequency $(0.12-0.14)$ by generation 300 , although their dynamics are very different. A sharp rise, stabilization, followed by a small decrease in the frequency of the aberrant chromosome by generation 150 are features of populations $0.85 /$ 0.64 that are polymorphic for the distorter. The frequency increases smoothly and slowly to generation 300 in population $0.64 / 0.64$ (Fig. 5b,c). The genotypic composition of the simulated populations for 250-300 generations is given in Table 4 .

\section{Dynamics of distorters in a polymorphic population}

A survey of the dynamics of spreading of the aberrant chromosome in simulated populations inevitably suggests the existence of selection against the stronger distorter. Indeed, the higher the level of meiotic transmission of the aberrant chromosome from heterozygous females to offspring, i.e. the stronger the distorter, the greater is the elimination rate of the normal homologue with the distorter. Therefore, in a population with the same initial concentration of dis-

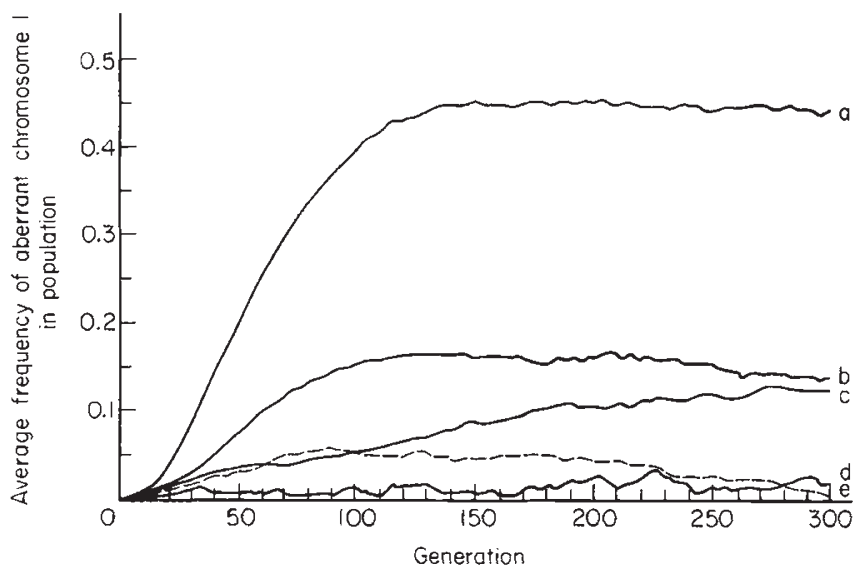

Fig. 5 The dynamics of the average frequency of aberrant chromosome 1 in populations with migration coefficient $k=0.25$ and distorters. (a) $0.85 / 0.85$; (b) $0.85 / 0.64$; (c) $0.64 /$ 0.64 ; (d) $0.64 / 0.5$; (e) $0.85 / 0.5$. Only the populations retaining the aberrant chromosome by generation 300 are considered.

torters of different strengths, the concentration of the weaker distorter would presumably increase and that of the stronger would decrease. This is plausible because genetic drift is known to be intense in small demes. The average simulations support this suggestion well (Fig. 6). In population $0.85 / 0.64$, the concentration of the 0.85 distorter falls and the distorter is almost entirely eliminated by generation 300 (Fig. 6b). The curve depicting the disappearance of a strong distorter is also consistently observed for polymorphic population $0.85 / 0.5$. Contrary to expectation, the concentration of distorter 0.85 increases during the first 30-40 generations (Fig. 6a). Note that only the populations retaining the chromosome for 300 generations are depicted. The aberrant chromosome persists to the end of the simulation procedure only in 10 of the 100 initial populations, and only by chance (genetic drift) is the frequency of the strong distorter increased. Subsequently, a decrease in the frequency of distorter 0.85 is the inevitable result of meiotic drive. No such increase in the frequency of the strong distorter was observed for populations $0.85 / 0.64$ because the aberrant chromosome could spread even in the case of a distorter concentration in excess of 0.64 . The level of meiotic drive was too low in the simulated populations polymorphic for distorters 0.64 and 0.5 to provide spreading and maintenance of the chromosome. Only in exclusive populations in which the concentration of distorter 0.64 did not exceed 50 per cent could we follow the dynamics of the aberrant chromosome. Of the 100 initial populations, just one retained the aberrant chromosome to generation 300 . Thus, elimination of the strong distorter was observed in all populations 
Table 4 The average concentrations of aberrant chromosome 1 and genotype frequencies in the populations from generations 250-300

\begin{tabular}{|c|c|c|c|c|c|}
\hline \multirow{2}{*}{$\begin{array}{l}\text { Distorters } \\
\text { in } \\
\text { population }\end{array}$} & \multirow{2}{*}{$\begin{array}{l}\text { Number of populations } \\
\text { retaining the } \\
\text { aberrant chromosome } \\
\text { by generation } 300\end{array}$} & \multicolumn{3}{|c|}{ Genotype frequencies } & \multirow{2}{*}{$\begin{array}{l}\text { Aberrant } \\
\text { chromosome } 1 \\
\text { concentration }\end{array}$} \\
\hline & & Is/Is & Is $/+$ & $+1+$ & \\
\hline $0.85-0.85$ & 47 & $0.11 \pm 0.00$ & $0.67 \pm 0.00$ & $0.22 \pm 0.00$ & $0.44 \pm 0.01$ \\
\hline $0.85-0.64$ & 34 & $0.02 \pm 0.00$ & $0.25 \pm 0.00$ & $0.73 \pm 0.01$ & $0.14 \pm 0.00$ \\
\hline $0.64-0.64$ & 22 & $0.01 \pm 0.00$ & $0.22 \pm 0.01$ & $0.77 \pm 0.01$ & $0.12 \pm 0.00$ \\
\hline $0.85-0.5$ & 10 & $0.00 \pm 0.00$ & $0.05 \pm 0.01$ & $0.95 \pm 0.01$ & $0.03 \pm 0.01$ \\
\hline $0.64-0.5$ & 1 & $0.00 \pm 0.00$ & $0.08 \pm 0.02$ & $0.92 \pm 0.02$ & $0.04 \pm 0.01$ \\
\hline
\end{tabular}

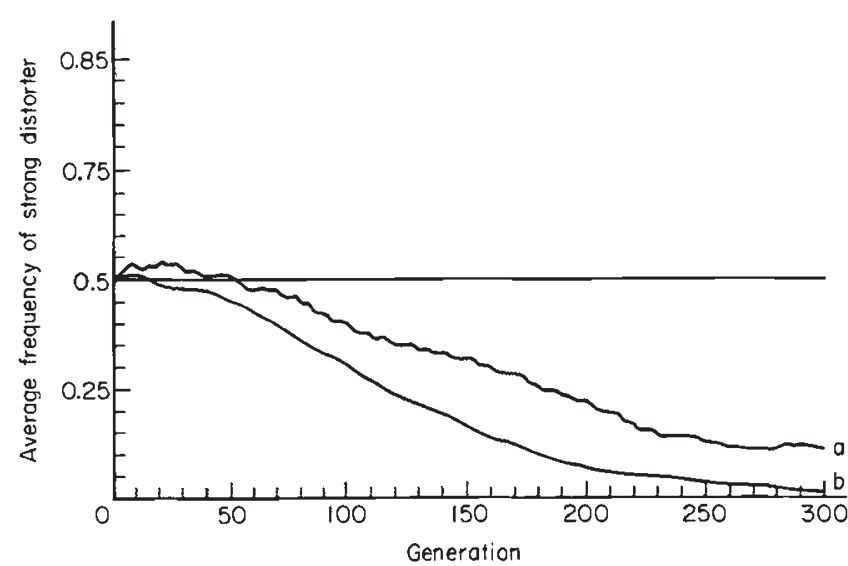

Fig. 6 The dynamics of the average frequency of the stronger distorter $(m=0.85)$ in populations polymorphic for the distorters. (a) $0.85 / 0.5$; (b) $0.85 / 0.64$.

polymorphic for the distorter, and this was due to its extinction by preferential transmission of the homologous aberrant chromosome 1 from heterozygous females to offspring.

\section{Frequencies of the aberrant chromosome in natural populations}

The estimated frequencies of genotypes and aberrant chromosome 1 in natural populations are summarized in Table 5. The aberrant chromosome was not observed in many populations. Note that it occurred in large cities: the populations most thoroughly studied were from Novosibirsk and Yakutsk, where the average frequencies of the aberrant chromosome were 0.26 and 0.22 , respectively. However, the samples from the two localities contained demes or groups of closely related demes greatly differing in aberrant chromosome frequencies. The frequencies of the chromosome were high (about 50 per cent) in some samples.

This analysis of natural mouse populations revealed mosaicism in the distribution pattern of aberrant chromosome 1 in the Asian populations of M.m. musculus.

\section{Discussion}

Recently, bearers of chromosome 1 with insertions have been encountered, first in M.m. domesticus and subsequently in M.m. musculus populations (Traut et al., 1984; Agulnik et al., 1988). Molecular and genetic analyses demonstrate a high degree of homology of the highly repetitive DNA sequences, and this suggests their common origin (Boldyreff et al., 1988; Weith et al., 1987). The two Mus semispecies differ in a large inversion present in M.m. musculus (Agulnik et al., 1990b; Winking et al., 1991).

Analysis of natural populations of M.m. musculus disclosed the occurrence of the aberrant chromosome in various localities of the Asian part of the country. A number of individuals, hetero- and homozygous for this chromosome, was found in Novosibirsk and Yakutsk, two Siberian cities remote from each other. Note that Novosibirsk and Yakutsk have had an influx of settlers migrating from the west and, consequently of mice, over the last 50-100 years. However, the aberrant chromosome 1 was not observed in many other populations (Table 5). It appears that the aberrant chromosome has a mosaic distribution in the range of M.m. musculus.

A survey of the evolutionary scenario of the origin and spreading of aberrant chromosome 1 in M.m. musculus suggests the following. Chromosome 1, with an amplified DNA segment, has a chance of spreading in the various populations of M.m. domesticus, and it introgressed into M.m. musculus some time ago. Thus an inversion at the insertion site may have evolved and a chromosome has arisen with new features including preferential transmission from heterozygous females (with a definite genotype) to their offspring, plus a decreased viability and fertility of homozygous females (Agulnik et al., 1993, b). The further evolutionary 
Table 5 Genotype frequencies from samples of natural mouse populations

\begin{tabular}{|c|c|c|c|c|c|}
\hline \multirow[b]{2}{*}{ Capture size } & \multirow{2}{*}{$\begin{array}{l}\text { Total } \\
\text { mice }\end{array}$} & \multicolumn{3}{|c|}{ Genotype frequencies $(\%)^{*}$} & \multirow{2}{*}{$\begin{array}{l}\text { Aberrant } \\
\text { chromosome } 1 \\
\text { frequency }(\%)\end{array}$} \\
\hline & & $+1+$ & Is $/+$ & Is/Is & \\
\hline \multicolumn{6}{|l|}{ Western Siberia } \\
\hline Novosibirsk including locality $\mathrm{OK}$ & 98 & $56.1(55)$ & $35.7(35)$ & $8.2(8)$ & 26.0 \\
\hline $\mathrm{OK}$ & 44 & $15.9(7)$ & $65.9(29)$ & $18.2(8)$ & 51.1 \\
\hline Omsk & $1 \dagger$ & - & $-(1)$ & - & - \\
\hline Tomsk & 37 & $100(37)$ & - & - & 0 \\
\hline $\begin{array}{l}\text { Altai territory } \\
\text { (settlement Cherga) }\end{array}$ & 26 & $100(26)$ & - & - & 0 \\
\hline \multicolumn{6}{|l|}{ Eastern Siberia } \\
\hline Yakutsk including locality 87 & 47 & $66.0(31)$ & $23.4(11)$ & $10.6(5)$ & 22.3 \\
\hline 87 & 15 & $26.7(4)$ & $46.7(7)$ & $26.7(4)$ & 50.0 \\
\hline $\begin{array}{l}\text { Krasnoyarsk territory } \\
\text { (settlement Nazarovo) }\end{array}$ & $4 \dagger$ & $-(4)$ & - & - & - \\
\hline $\begin{array}{l}\text { Irkutsk region } \\
\quad \text { (settlement Ust-Koot) }\end{array}$ & $1 \dagger$ & $-(1)$ & - & - & - \\
\hline Primorya territory & $3 \dagger$ & $-(3)$ & - & - & - \\
\hline Tuva & $2 \dagger$ & $-(2)$ & - & - & - \\
\hline \multicolumn{6}{|l|}{ Middle Asia } \\
\hline Turkmenistan including Ashhabad & 35 & $97.1(34)$ & $22.9(1)$ & - & 1.4 \\
\hline Ashhabad & $2 \dagger$ & $-(1)$ & $-(1)$ & - & - \\
\hline Uzbekistan & 26 & $100(26)$ & - & - & 0 \\
\hline Alma-Ata & $2 \dagger$ & $-(2)$ & - & - & - \\
\hline
\end{tabular}

*The number of mice with the designated genotype is given parentheses.

$\dagger$ The sample is too small for estimation of genotype frequency and concentration of aberrant chromosome 1 .

fate of the aberrant chromosome is much dependent on these features, which, when counteracting, give an impetus to the formation of a balanced polymorphism. The present computer simulation of the spreading of the aberrant chromosome in the demes and populations has yielded results that allow us to identify two factors mainly affecting the process. The first is the value of the meiotic drive and the second is that of the rate of migration. At high values, the aberrant chromosome spreads widely in the populations. The effect of deme size on the spread of the aberrant chromosome in the population is restricted to the first $10-15$ generations. The large the deme, the more probable the loss of the aberrant chromosome from the initial deme and, consequently, the less probable its spread in the population.

Comparisons of the time course of elimination of the aberrant chromosome from a 'small' deme and a population composed of such demes show a high probability of its retention presumably because of immigration. In fact, the aberrant chromosome was dramatically eliminated from the 'small' demes at a drive level of 0.85 up to generation 300 so that only 8 per cent of the demes retained the chromosome (Fig. 2b). In the corresponding population, a stable state is formed as early as 5-10 generations after the simulation was stable, and approximately 50 per cent of the populations retain the aberrant chromosome (Fig. 4a). This is brought out more clearly in comparisons of 'small' demes with a drive level of 0.64 (Fig. 2c) with populations composed of these demes (Fig. 4c). In such demes, the aberrant chromosome is completely eliminated by generation 120 , whereas it is stably retained in 22 per cent of the corresponding population.

Another result of the simulation is that the equilibrium frequencies for the 'small' demes, with $m=0.85$, and the population composed of such demes are close, being about 0.45 (Tables $1 \mathrm{a}, \mathrm{b}$ and $4 \mathrm{a}$ ). After reaching stable genotype frequencies, a stationary regime is established both in the demes and populations (Figs $3 \mathrm{a}$ and 5a). This stability is attained in the populations (Fig. 5c) and not in the demes (Fig. 3b) when the drive level is 0.64 .

Our salient finding is the formation of stable equilibrium points for genotype frequencies in the simulated populations. These points correspond to different distorters. The frequency of the aberrant chromosome at this point is 0.44 (see above) for a population monomorphic for distorter 0.85 (Table 4a, Fig. 5a). Another equilibrium point is formed for the initially mono- 
morphic populations with a distorter of 0.64 , yet another for the initially polymorphic $0.85 / 0.64$. Thus, the initial state of a population is highly relevant to the frequency of the aberrant chromosome and it is irrelevant to the final state (Fig. 5b,c) because, as demonstrated above, the populations polymorphic for the stronger distorter eventually lose it and become monomorphic. Furthermore, the initial concentration of the aberrant chromosome in the population also has no effect on the final state of the genotypic equilibrium points. In populations $(m=0.64)$, in which the initial concentration of the aberrant chromosome was 50 per cent, equilibrium was attained at a frequency of 0.14 by generation 20-30. The aberrant chromosome will certainly be lost from every polymorphic population with a distorter of 0.5 , and all such populations therefore attain the state of genotypic equilibrium. Thus, we obtained an affirmative answer to the question of whether an aberrant chromosome, once it has arisen under the above conditions, can spread throughout the range occupied by Mus musculus.

The simulation results also suggest that, for a relatively short time, e.g. hundreds of generations, the aberrant chromosome, once arisen with the described features, has a high probability of spreading over a vast territory. Thus, it may be assumed that chromosome rearrangement arose quite recently. The mosaic pattern of distribution and the frequencies of the aberrant chromosome in natural populations are also not at variance with this assumption. Other hypothetical explanations for the origin and spread of the aberrant chromosome are not ruled out. It is encouraging that in some of the natural populations there are demes with genotype frequencies and aberrant chromosome concentrations that are not different from those derived from the model (Table 5). This argues in favour of the validity of the premise on which the computer model is based and also allows us to make some predictions concerning how the aberrant chromosome continues to spread in the populations of $M . m$. musculus.

\section{Acknowledgements}

The authors would like to thank Drs A. Polyakov and I. Gorlov for discussing the manuscript. They are also grateful to Mrs A. Fadeeva for translating the paper into English.

\section{References}

AGULNIK, S., AGULNIK, A. AND RUVINSKY, A. 1990a. Meiotic drive in female mice heterozygous for the HSR inserts on chromosome 1. Genet. Res., 55, 97-100.

AGULNIK, S., BORODIN, P., GORLOV, I., LADYGINA, T. AND PAK, s. $1990 \mathrm{~b}$. The origin of a double insertion of homogeneously staining regions in the house mouse (Mus musculus musculus). Heredity, 65, 265-267.

AGULNIK, S., GORLOV, I. AND AGULNIK, A. 1988. New variant of chromosome 1 in the house mouse Mus musculus. Tsitologia, 30, 773-776. (In Russian.)

AGULNIK, S. I., SABANTSEV, I. D., ORLOVA, G. V. AND RUVINSKY, A. O. 1993. Meiotic drive on aberrant chromosome 1 is determined by a linked distorter in the mouse. Genet. Res. (in press a).

AGULNIK, S. I., SABANTSEV, I. D. AND RUVINSKY, A. O. 1993 Effect of sperm genotype on chromatid segregation in female mice heterozygous for aberrant chromosome 1. Genet. Res. (in press b).

BOLDYREFF, B., WINKING, H., WEITH, A. AND TRAUT, w. 1988. Evidence for in situ amplification of a germ line homogeneously staining region in the mouse. Cytogenet. Cell Genet., 47, 84-85.

BRITTNACHER, J. G. AND GANETZKY, B. 1989. On the components of segregation distortion in Drosophila melanogaster. Genetics, 121, 739-750.

CROW, J. F. 1988. Perspectives. Anecdotal, historical and critical commentaries on genetics. The ultraselfish genes. Genetics, 118, 389-391.

DYAKONOV, v. P. 1987. A Reference Book for Algorithms and Programmes on BASIC for Personal Computers, Nauka, Moscow. (In Russian.)

DYBAN, A. P. AND BARANOV, V. S. 1978. Cytogenetics of Mammalian Development, Nauka, Moscow, pp. 216-218. (In Russian.)

LEWONTIN, R. C. 1962. Interdeme selection controlling a polymorphism in the house mouse. Am. Nat., 96, 65-78.

LEWONTIN, R. C. AND DUNN, L. C. 1960 . The evolutionary dynamics of a polymorphism in the house mouse. Genetics, 45 , 705-722.

PETRAS, M. L. 1967. Studies of natural populations of Mus. 1. Biochemical polymorphisms and their bearing on breeding structure. Evolution, 21, 259-274.

SILVER, L. M. 1985. Mouse t haplotypes. Ann. Rev. Genet., 19, 179-208.

TRAUT, W., WINKING, H. AND ADOLPH, s. 1984. An extra segment in chromosome 1 of wild Mus musculus: C-band positive homogeneously staining region. Cytogenet. Cell Genet., 38, 290-297.

WEITH, A., WINKING, A., BRACKMANN, B., BOLDYREFF, B. AND TRAUT, w. 1987. Microclones from a mouse germ line HSR detect amplification and complex rearrangements of DNA sequences. The EMBO Journal, 6, 1295-1300.

WINKING, H., BOSTELMANN, H. AND FREDGA, K. 1991a. Incidence of double-band HSRs in chromosome 1 of the house mouse, Mus musculus musculus, from Oland (Sweden): a population study. Hereditas, 114, 111-116.

WINKING, H., WEITH, A., BOLDYREFF, B., MORIWAKI, K., FREDGA, $\mathrm{K}$ AND TRAUT, w. 1991b. Polymorphic HSRs in chromosome 1 of the two semispecies Mus musculus musculus and Mus musculus domesticus have a common origin in ancestral population. Chromosoma, 100, 147-151.

YAKIMENKO, L. AND KOROBITSYNA, K. 1988. A rare variant of chromosome 1 in house mouse: occurrence of two extra heterochromatin segments. Genetika, 24, 376-378. (In Russian.) 